Volume 4 • Nomor 2 • Februari 2021

Pege (Hal.) : 168 - 182

(C) Universitas Pamulang

JL.Surya Kencana No.1 Pamulang, Tangerang Selatan - Banten

Telp. (021) 7412566, Fax (021) 7412491

website. : Email : jurnalmarketing.unpam@gmail.com

\title{
Analisis Faktor-Faktor Penentu Keputusan Pembelian Pada Kedai Kopi Nol Derajat Cikampek Karawang
}

\author{
A Faizal Muzakki', Eman Sulaeman² \\ Universitas Singaperbangsa Karawang \\ Email:161063102001@student.unsika.ac.id, ah.humaedi@gmail.com
}

\begin{abstract}
Abstrak. Riset ini bermaksud agar mengatahui faktor-faktor penentu keputusan pembelian pada Kedai Kopi Nol derajat Cikampek Karawang. Populasi dari penelitian ini adalah pelanggan Kedai Kopi Nol derajat Cikampek Karawang dengan total responden sejumlah 100 orang. Riset ini memakai teknik non probability sampling dan teknik purposive sampling. Penyatuan informasi dengan penyebaran Kuisioner dan diolah memakai teknik analisis faktor. Sedangkan hasil analisis yang didapatkan menunjukan bahwa faktor-faktor penentu keputusan pembelian pada Kedai Kopi Nol derajat Cikampek Karawang adalah faktor satu Performance (Kinerja), faktor dua Akses, faktor tiga Features (fitur) ,faktor empat Publisitas and hubungan Masyarakat . Keempat faktor yang tertera mendapatkan loading factor melebihi dari 0,5 dengan kumulatif persentase varian sejumlah $66,118 \%$ sedangkan sisanya $33,882 \%$ disebabkan akibat bagian tidak diteliti. Faktor utama berpengaruh pada penentu keputusan pembelian pada Kedai Kopi Nol derajat Cikampek Karawang adalah faktor Performance (Kinerja) dengan eigen value yang didapatkan sejumlah 8,761 dan cumulative pernetage variance sejumlah $46,111 \%$.
\end{abstract}

\section{Kata kunci: Analisis Faktor; Keputusan pembelian}

Abstract. This research orders to find out the determinants of purchasing decisions at the Coffee Shop Nol derajat Cikampek Karawang. The population of this study were customers of the Coffee Shop Nol derajat Cikampek Karawang with a total of 100 respondents. This research uses non probability sampling techniques and purposive sampling techniques. Unification of information by distributing questionnaires and processed using factor analysis techniques. While the results of the analysis obtained show that the determinants of purchasing decisions at the Coffee Shop Nol derajar Cikampek Karawang are one performance factor, two access factors, three features factor (features), publicity factor four and public relations. The four factors listed have a loading factor exceeding 0.5 with a cumulative proportion of the number of $66.118 \%$ while the remaining $33.882 \%$ is due to the part not being examined. The purchasing factor that influences the decision making at the Coffee Shop Nol derajat Cikampek Karawangis the performance factor with the eigenvalues obtained of 8.761 and the cumulative pernetage variance of $46.111 \%$.

Keywords: Factor Analysis; Purchasing Decision 


\section{A. PENDAHULUAN}

Kebutuhan dan keinginan manusia pada waktu ini mengupayakan agar bisa meniru pada era jaman modern ini. Bahkan dengan mengikuti era jaman modern sekarang setiap orang mengiginkan gaya hidup yang menarik. Contohnya, trend sekarang untuk meminum kopi menjadi semakin berkembang. Bahkan Kopi sekarang menjadi meningkat pesat dengan jenis minuman cukup populer dan juga pengonsumsi kopi bisa berbagai kalangan usia, kopi dapat diperoleh dibergabai tempat akan tetapi di era jaman modern ini sudah banyak pembisnis kopi yang berdiri bisa dikatakan dengan lapak kopi atau kedai kopi. Coffe shop dapat di temukan di berbagai macam tempat di sekitar kita, dari mulai di perkotaan sampai di pinggir kota. Dengan demikian, terjadi perubahan pada zaman sekarang pola konsumsi masyarakat lebih mengonsumsi makanan modern dibandingkan dengan makanan tradisional dengan mengubah gaya hidup memilih proses yang pembuatannya lebih praktis seperti halnya mengkonsumsi makanan atau minuman yang berkemasan. Kesempatan seperti ini tepat dalam pembisnis memanfaatkan kejadian yang ada dalam ikut terjun kedalam usaha makanan sangat berlomba-lomba bisa memenuhi kebutuhan maupun keinginan pelanggan dengan cara menawarkan barang sehingga bisa bersaingan dalam dunia usaha

Keputusan pembelian adalah penentuan pelanggan perihal sumber tentang brand yang berada di dalamnya (adhi, NP Endang, \& Shanti , 2016). Pelanggan mengambil keputusan dalam membeli suatau barang biasanya menimbangkan faktor-faktor seperti produk, harga, lokasi dan promosi dahulu. Sehingga, bagi pembisnis harus bisa menganalisis segala sesuatu yang di sukai atau tingkah laku pelanggan saat menentukan pembelian.maka dari itu pembisnis harus banyak mengetahui setiap variabel-variabel dalam melakukan bisnis yang di jalankannya.

Menurut Kotler (2003:202) dalam Dedy Ansari Harahap (2015:228) perilaku-perilaku yang bisa mengakibatkan dalam keputusan pembelian ada empat seperti budaya, psikologis dan sosial pribadi. Maka dari itu yang menjadi faktor keputusan pembelian yang mempertimbangkan dalam penelitian ini yaitu pruduk, harga, tempat, dan promosi. Sedangkan menurut Dedy Ansari Harahap (2015:228) ada beberapa faktor untuk menentukan faktor-faktor penentu keputusan pembelian yang pertama biasanya produk sebagai inti dari setiap pembelian sebagai penetap nilai suatu penentu pembelian. Pada penelitian ini dengan menghasilkan rasa sesuai selera atau enak bisa menjadi daya tarik untuk Konsumen, dan juga agar bisa mempercantik tata penyajian yang menarik.

Faktor selanutnya yang kedua dalam penentu keputusan pembelian biasanya terdapat pada harga. Harga bisa merupakan petunjuk kadar barang. Pengunjung rata-rata mengidentifikasikan harga barang yang tinggi harganya harus sesuai baarang yang didapatkan begitupun sebaliknya. Kebanyakan pelanggan pada saat akan membeli dengan melihat tarif atau harga tentukan sesuai atau tidaknya, dengan itu untuk menentukan harga yang dijual lebih baik melihat dengan kualitas yang didapatkan. Dengan mencantumkan harga yang terlalu tinggi dan tidak sesuai dengan kualitasnya maka pelanggan secara tidak langsung berpindah ke brand lain.

Faktor ketiga ada lokasi menjadi faktor yang berkuasa pada penentuan yang bisa dicapai pelanggan guna mendapatkan barang. Tempat yang dibilang gampang di jangkau bagi pelanggan dapat menjadi salah satu kunci dalam keputusan pembelian. Termasuk pada usaha kopi ini. Sebelum seseorang memutuskan untuk mengkonsumsi kopi mereka juga akan mempertimbangkan lokasi caffe kopi yang terjangkau. 
Selanjutnya faktor yang ke empat yaitu promosi menurut Swastha dan Sukotjo (2007:222) dalam Rifki Fachrurozi (2014:6) pada pemasaran diciptakan suatu sumber infoinfo yang dituju untuk menangkap daya tarik seseorang agar mengetahuinya. Selanjutnya pendapat buchari alma (2005:179) dalam Lydia goenadhi (2011:156) promosi adalah jalan untuk menyampaikan sumber informasi yang ditujukan untuk meyakinkan kepada pelanggan. Dengan itu promosi bisa untuk meyakinkan, mengingatkan ataupun memberi perhatian kepada calon pelanggan serta bisa menjadikan untuk menaikan omset pada suatu penjualan.

Lalu menurut Totok Murdoyo (2014) Karakteristik yang ada pada seseorang dapat mempengaruhi keputusan pembelian yang dilakukan pribadi orang tersebut. Beberapa karateristik individu yang mempengaruhi keputusan pembelian yaitu umur maupun tahapan cicyle kehidupan, kegiatan, situasi perdagangan serta kehidupan dalam integritas maupun rancangan. Hal pribadi dalam pengambilan keputusan pembelian seseorang dalam menentukan mana yang akan dituju pasti mempunyai presepsi berbeda ketika ingin membeli dan menentukannya, oleh karena itu kepribadian dan konsep yang ada dalam dirinya yang bisa menentukanya. Faktor selanjutnya faktor psikologis, memerlukan yang harus dipenuhi oleh seseorang tidak selamanya bersifat psikologis. Seperti yang bisa terlihat oleh semua orang konsumen bisa menentukan untuk mengambil keputusan pembelian terhadap kedai-kedai kopi yang akan di kunjunginya, pasti sudah mempunyai persepsi tersendiri dan juga motivasi kenapa dia harus memilih kedai kopi tersebut dari pada yang lainnya. Keputusan para konsumen menjadi salah satu hal yang memastikan daya saing untuk memenangkan konkuren terjadi karena konsumen tidak puas pada apa yang meraka dapatkan dapat menyebabkan memilih kedai lain dan bisa saja menjadi kerugian bagi kedai tersebut keadaan ini di dukung dengan tingkat rasa, lokasi terjangkau dan juga kenyamanan yang diberikan menjadi tujuan utama sehingga konsumen akan mudah untuk berkunjung kembali

Menurut uraian tersebut, dengan itu maksud penulis sangat terkesan bisa memahami dan mengkajian Faktor-faktor apa saja penentu keputuasan pembelian pada kedai kopi Nol derajat Cikampek Karawang .

Perumusan Masalah pada penelitian ini ditemukan dalam latar belakang masalah, dengan itu dapat diambil simpulkan terdapat pendahuluan permasalahan menjadi kesimpulan masalah ini: (a) seberapa besar faktor-factor yang sangat utama pada proses pengambilam keputusan pembeliian pada pembelian kopi di kedai kopi Nol derajat ? (b) seberapa besar faktor-faktor penentu keputusam pembelian pada kedai kopi Nol derajat ?

Tujuan Penelitian ini berdasarkan pada kajian masalah, bahwa arah dari riset ini sebagai berikut : (a) Menganalisis faktor-faktor utama untuk metode penentuan keputusann pembelian pada pembelian kopi di kedai Kopi Nol derajat ? (b) Menganalisis faktor-faktor penentu keputusan pembelian dalam pembelian kopi di kedai kopi Nol derajat ?

\section{B. KAJIAN LITERATUR}

\section{Keputusan Pembelian}

Menurut Arsianto Balawera (2013:2119) Keputusan pembelian menjadi suatu konsep pada perilaku pembelian yang mana konsumen mementukan untuk memilih atau melakukan suatu hal. Dengan melakukan pembelian ataupun memanfaakan produk atau jasa tertentu.

Dalam penentu keputusan pembelian ada enam indikator keputusan pembelian menurut menurut Kotler dan Keller (2009:178) pada Indri Yanti (2019:43) terdapat enam 
komponen dalam keputusan pembelian sebagai berikut: (a) pilihan brand (b) Metode pembayaran (c) Pilihan pemasok. (d) Jumlah pembelian. (e) Waktu pembelian. (f) Pilihan produk

\section{Kualitas Produk}

Menurut Nitisusastro (2012:162) dalam Putri Luhmey (2018:4) kualitas produk merupakan keistimewaan barang maupun jasa yang bersandar atas kemampuanya agar memenuhi keinginan pelanggan untuk diuraikan maupun diimplementasikan. Dan penanda kualitas produk adalah Menurut mullins, Orville, Larreche, dan boyd (2005:422) pada Basrah Saidami dan Samsul Ariifin (2012:5) yaitu : (a) Performaance : ialah bersangkutan dengan pada keunikan utama dalam seuatu barang. (b) Durability (ketahanan): ialah durasi daya tahan barang tersebut bertahan sebelom barang tersebut perlu di ganti. (c) Conformance to speciifications (kesesuaian dengan spesifikasi): yang berarti seberapa jauh barang tersebut dapat memberikan spesifikasi atau tak ada yang terdapat rusak pada barang tersebut. (d) : karakteristik merupakan keistimewaan barang untuk diatur dengan melengkapi manfaat barang maupun ketertarikan minat pelanggan terhadap pembelian barang. (e) Reability (Reabilitas): merupakan peluang jika barang hendak berfungsi dengn baiik maupun tidaknya pada kurun waktu tertentu. (f) Aesthetics (Estika): ialah bersangkutan pada bagaimana penampakan barang tersebut. (g) Perceived quality (kesan kualitas): suka disebut adalah efek pada penerapan pengukuraan yang dilaksanakan secara tidak tepat karena terdapat kemungkinan jika pelanggan tidak paham maupun kurangnya penjelasan berkaitan terhadap barang tersebut.

\section{Harga}

Menurut Buchari Alma (2018:171) harga yaitu nominal intrinsik pada barang yang diganti dengan uang. Dan terdapat indikator harga menurut Wibowo dan Karimah (2012:5) dalam Agus Susanto (2013:21) terdapat empat indikator harga ialah : (a) Penetap Harga. (b) Harga yang relatife sangat rendah. (c) Kewajaraan harga. (d) Kesesuaian loyalitas dan harga sesuai dengan manfaat.

\section{Lokasi}

Sedangkan Menurut Sibarani, Armayanti, Irwansyah, Suharianto (2019:41) lokasi yaitu tataletak suatu tempat yang berdiri permukaan tanah untuk memasarkan atau melayani pelanggan. Lokasi merupakan posisi dimana setiap orang bisa menemui untuk melakukan pembelian pada suatu barang atau jasa yang mempunyai tempat yang strategis dan juga suasana yang bagus. Dan serta terdapat indikator lokasi Sedangkan menurut Hendra Fure (2013:276) dalam Eri Nurul Badri (2018:38) Indikator lokasi yaitu : (a) Lokasi yang gampang terlihat. (b) Mempunyai ruang parkir. (c) Mempunyai posisi yang memadai. (d) Kenyamanan di sekitiar lingkungan.

\section{Promosi}

Menurut Buchari Alma (2018:181) menjelaskan bahwa promosi yaitu semacam berhubungan langsung yang dapat menjelaskan sesuatu hal dengan memastikan calon pelanggan berupa barang ataupun jasa. Dan juga terdapat indikator promosi menurut Hersona, dkk (2013:1150) dalam Agus Susanto (2013:13) ditemukan 5 dimensi agar bisa dijadikan guna pengukuran pada promosi ialah: (a) penjualan pribadi. (b) periklanan. (c) Promosi penjualan. (d) Public relations. (e). Direct marketing.

\section{Kerangka Pemikiran}

Menurut Sugiyono (2010:60-61) kerangka pemikiran merupakan hal pertama supaya rancangan pemikiran dapat memastikan sesama ilmuwan, yaitu pola pikir yang masuk 
logika saat menyusun sebuah rangka pemikiran yang menghasilkan kesimpulan agar terbentuk hipotesis. Maka dari itu, rancangan pemikiran menjadi sintesa terhadap signifikansi antara variabel yang diisusun dari banyaknya teori setelah digambarkankan. Bersumber pada konsep-konsep yang sudah digambarkan, kemudian setelah ditelaah dengan kritis dan tertata, maka menimbulkan sintesa dari hubungan pervariabel yang diteliiti. Selanjutnya dibawah ini menjelaskan tentang paradigma pada riset ini sebagai berikut:

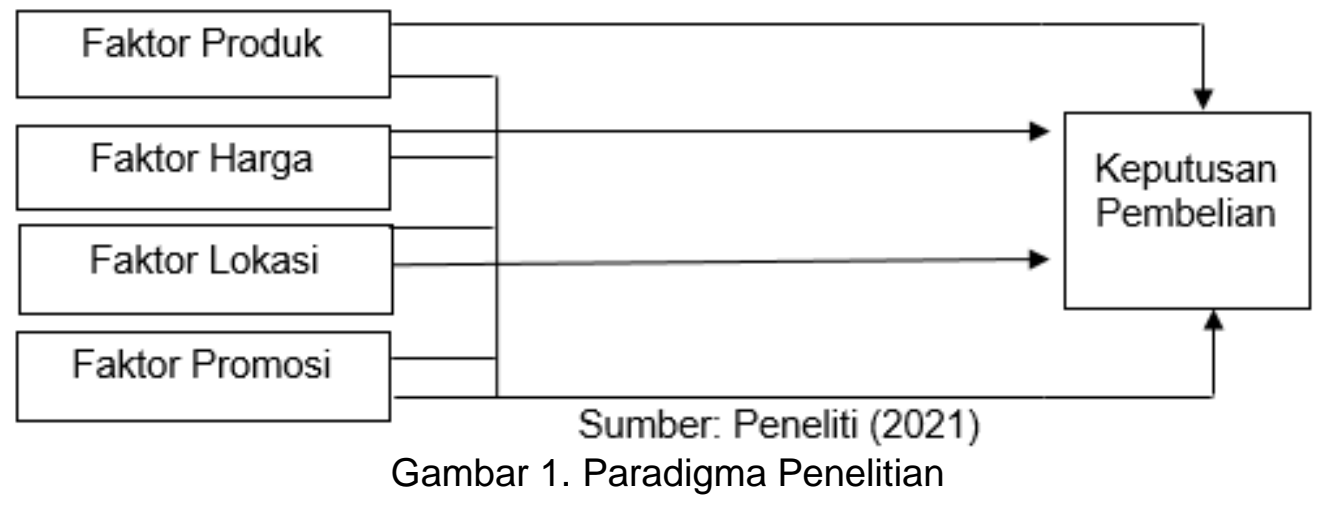

\section{METODOLOGI PENELITIAN}

Riset ini di lakukan di kedai kopi Nol derajat Cikampek Karawang, Populasi dalam riset ini yaitu pengunjung kedai kopi Nol derajat cikampek Karwang dengan jumlah populasi sebanyak 13.514 dengan pengumpulam mulai dari Maret sampai februari 2020, dan berkaitan dengan masalah yang ada penelitian ini berjutuan agar mengetahui penentu faktor-faktor apa saja yang muncul pada kedai Kopi Nol derajat Cikampek karawang. Penelitian ini mengacu pada rumus Roscoe. Roscoee dalam Sugiiyono (2010:131) dalam Nuryati (2015:5) berikut ini saran - saran tentang ukurna sampel : (a) Hal yang layak dalam penelitian ini ukuran sampel itu dari tiga puluh (30) sampai limaratus (500). (b) Jika sample di klasifikasikan (seperti : laki-laki dan perempuan, pegawai, lalu sebagainya) kemudian total bagian sample perkategori min tiga puluh (30). (c) Apabila riset menggunakan analisis multivariate lalu jumlah anggota sampel min 10x dari total variable yang diianalisis. contohnya variable riset tersebut ada lima (dependen dan independen), bahwa total dari bagian sample $=10 \times 5=50$. Bersumber pada pendapat tersebut, jadi peneliti menerapkan total sample pada riset ini sejumlah 100 orang. karena riset ini terdapat dari tiga kategori yaitu, umur, jenis kelamin (pria dan wanita) serta pendidikan terakhir maka sampel minimal yang harus dikenai yaitu 90 orang. Dengan begitu peneliti mengubah menjadi 100 orang karena dengan mengubah 100 orang telah memenuhi syarat-syarat yang ditentukan. Teknik sampling yang dipakai pada penelitian yaitu teknik Non probabiiity Sampling dengan method Purposive sampling serta metode Kuantitatif. Dari riset ini peneliti memakai teknik penyatuan data dengan peninjauan langsung dilapangan buat menghasilkan keterangan dan fakta secara spontan di kedai kopi Nol derajat dengan cara Wawancara (interview) dengan pemilik kedai kopi Nol derajat dan memyebarkan Kuisioner kepada pengunjung kedai kopi Nol derajat Cikampek Karawang. Adapun sofware yang gunakan dalam penelitian ini adalah SPSS16. 


\section{HASIL DAN PEMBAHASAN}

\section{Karateristik Responden}

Objek pada riset ini yaitu sebagai pelanggan yang berkunjung serta membeli di kedai kopi Nol derajat. Dari sampel yang didapatkan sebesar 100 orang responden dapat di kelompokan dibawah ini:

Tabel 1. Data Responden Berdasarkan Jenis Kelamin

\begin{tabular}{|l|l|l|l|}
\hline No & Jenis Kelamin & Jumlah & Persentase \\
\hline 1 & Laki-laki & 62 & $62 \%$ \\
\hline 2 & Perempuan & 38 & $38 \%$ \\
\hline Total & 100 & $100 \%$ \\
\hline
\end{tabular}

Sumber : Hasil pengolahan data, Peneliti 2020

Dari Tabel 1 bisa disimpulkan maka sebagian besar responden merupakan berjenis kelamin laki-laki memperoleh persentase $62 \%$ pada jumlah 62 orang dan pada jenis kelamin perempuan memperoleh persentase 38\% dengan jumlah $38 \%$ orang.

Tabel 2. Data Responden Berdasarkan Usia

\begin{tabular}{|l|l|l|l|}
\hline No & Usia & Jumlah & Persentase \\
\hline 1 & $15-20$ Tahun & 6 & $6 \%$ \\
\hline 3 & $21-25$ Tahun & 77 & $77 \%$ \\
\hline 4 & $26-30$ Tahun & 11 & $11 \%$ \\
\hline Total & $>31$ & 6 & $6 \%$ \\
\hline
\end{tabular}

Sumber : Hasil pengolahan data, peneliti 2020

Dari tabel 2 dapat disimpulkan maka sebagian besar responden pada riset ini ada di usia 21-25 Tahun dengan jumlah 77 orang responden dan memperoleh persentase $77 \%$, lalu pada usia 26-30 Tahun mendapatkan jumlah 11 orang responden dengan persentase $11 \%$, sedangkan pada umur 15-20 Tahun mendapatkan jumlah 6 orang responden dengan persentase $6 \%$, dan pada umur $>31$ Tahun mendapatkan jumlah 6 orang mendapatkan persentase $6 \%$. 
ISSN NO. (PRINT) 2598-0823, (ONLINE) 2598-2893

Tabel 3. Data Responden Berdasarkan Pendidikan Terakhir

\begin{tabular}{|l|l|l|l|}
\hline No & Pendidikan Terakhir & Jumlah & Persentase \\
\hline 1 & SMAISMK & 60 & $60 \%$ \\
\hline 2 & DII & 1 & $1 \%$ \\
\hline 3 & DIII & 10 & $10 \%$ \\
\hline 4 & S1 & 28 & $28 \%$ \\
\hline 5 & S2 & 1 & $1 \%$ \\
\hline Total & & 100 & $100 \%$ \\
\hline
\end{tabular}

Sumber : Hasil pengolahan data, peneliti 2020

Dari Tabel 3 bisa disimpulkan maka sebagian besar responden yang berkunjung ke kedai kopi Nol derajat lulusan SMA/SMK dengan jumlah 60 orang dan memperoleh persentase $60 \%$, lalu lulusan S1 dengan total 28 orang dan memperoleh persentase $28 \%$, lulusan DIII dengan total 10 orang dan mendapatkan persentase $10 \%$, sedangkan lulusan DII dengan total 1 orang dan memperoleh persentase $1 \%$ dan S1 dengan total 1 orang dengan persentase $1 \%$.

\section{Uji Validitas}

Tabel 4. Hasil Uji Validitas

\begin{tabular}{|c|c|c|c|}
\hline Indikator & r hitung & r kritis & Kriteria \\
\hline Performance (Kinerja) & 0,747 & 0,3 & Valid \\
\hline Features (fitur) & 0.589 & 0,3 & Valid \\
\hline $\begin{array}{l}\text { Conformance to specification (Kesesuaian } \\
\text { dengan spesifikasi }\end{array}$ & 0,764 & 0,3 & Valid \\
\hline Aesthetios (Estika) & 0,753 & 0,3 & Valid \\
\hline Keterjangkauan Harga & 0,670 & 0,3 & Valid \\
\hline Kewajaran Harga & 0,692 & 0,3 & Valid \\
\hline Kesesuaian Harga dengan Kualitas Produk & 0,719 & 0,3 & Valid \\
\hline $\begin{array}{l}\text { Kesesuaian Harga dengan Manfaat yang } \\
\text { dihasilkan }\end{array}$ & 0,713 & 0,3 & Valid \\
\hline Akses & 0,613 & 0,3 & Valid \\
\hline Visibinitas & 0,663 & 0,3 & Valid \\
\hline Lalu lintas (traffic) & 0,647 & 0,3 & Valid \\
\hline Tempat parkir yang luas, nyaman, dan aman & 0,694 & 0,3 & Valid \\
\hline Lingkungan & 0,662 & 0,3 & Valid \\
\hline Advertising (Iklan) & 0,683 & 0,3 & Valid \\
\hline Personal Seling (Penjualan pribadi) & 0,698 & 0,3 & Valid \\
\hline Promosi penjualan & 0,650 & 0,3 & Valid \\
\hline Publisitas dan hubungan Masyarakat & 0,670 & 0,3 & Valid \\
\hline $\begin{array}{l}\text { Word of mounth (Informasi dari mulut ke } \\
\text { mulut }\end{array}$ & 0,564 & 0,3 & Valid \\
\hline Pemasaran langsung & 0,668 & 0,3 & Valid \\
\hline
\end{tabular}

Sumber : Hasil pengolahan Uji Validitas, Peneliti 2020 
Bersumber pada tabel 4 dapat dilihat maka dari 19 indikator yang ada tersebut menyatakan valid dikarenakan $r$ hitung dari semua pernyataan diatas melebihi $r$ kritis $(r>0,30)$.

\section{Uji Reliabilitas}

Tabel 5. Hasil Uji Reliabilitas

\begin{tabular}{|l|l|l|l|}
\hline Variabel & r hitung & r kritis & Kriteria \\
\hline Keputusan pembelian & 0,933 & 0,60 & Reliabel \\
\hline
\end{tabular}

Sumber : Hasil Pengolahan Uji Reliabilitas, Peneliti 2020

Pada Tabel 5 efek dari uji reliabilitas menunjukan bahwa variable keputusan pembelian memiliki $r$ hitung $>r$ kritis. Variabel keputusan pembelian memiliki $r$ hitung 0,933 maka variabel dinyatakan reliabel.

\section{Uji Normalitas}

Bermaksud agar mengetahui normal ataupun tidak normalnya suatu indiaktor dengan menggunakan metode kolmogorov-Smirnov. Data yang baik lalu cukup untuk memperlihatkan jenis-jenis model penelitian tersebut adalah data yang memiliki $\alpha$ hitung $>$ 0.05 maka variable tertera mengikuti distribusi normal. kemudian adalah keputusan uji normalitas variable pada riset ini :

Tabel 6

Hasil Uji Normalitas

\begin{tabular}{|l|l|l|l|}
\hline \multirow{2}{*}{ Varibael } & \multicolumn{2}{|l|}{ Koimogorov Smimov } & \multirow{2}{*}{ Kriteria } \\
\cline { 2 - 4 } & a hitung & a kritis & \\
\hline Keputusan Pembelian & 0,420 & 0,05 & Distribusi Norma \\
\hline
\end{tabular}

Sumber : Hasil pengolahan Uji Normalitas, Peneliti 2020

Pada tabel 6 menunjukan bahwa hasil uji normalitas setiap varibael memiliki nilai $\alpha$ hitung $>$ a kritis. Variabel keputusan pembelian memiliki a hitung sebesar 0,420 maka variabel keputusan pembelian dinyatakan mengikuti sebaran data normal.

\section{D.5. Analisis Faktor}

Langkah awal pada analisis faktor yaitu menilai indikator apa saja yang dianggap layak dilakukan pada riset ini dengan memasukan seluruh indikator yang tersedia selanjutnya indikator-indikator itu dikenakan sejumlah pengujian sebagai berikut :

Analisis Kaiser Uji Mayer Kmo And Barletts Test

Dibawah ialah merupakan hasil Kaiser uji Mayer KMO and Barlettss Test telah diolah menggunakan SPSS 16 yaitu :

Tabel 7 . KMO and Bartlett's Test

\begin{tabular}{|l|l|l|}
\hline Kaiser-Meyer-Qlkin Measure of Sampling Adequacy. & .879 \\
\hline Bartlett's Test of Sphericity & Approx. Chi-Square & $1.111 \mathrm{E}$ \\
\hline & Df & 171 \\
& Sig. & .000 \\
\hline
\end{tabular}

Sumber : Hasil pengolahan data SPSS 16, Peneliti 2020 
Menurut Tabel 7 menunjukan bahwa nilai yang diperoleh dari analisis $\mathrm{KMO}$ and Barlett's Test adalah 0,879 dan dilihat dari nilai Barlett's Test menunjukan nilai yang besar dengan nilai signifikan 0 . Oleh karena itu dapat dijelaskan bahwa instrumen ini valid sebab telah melebihi nilai 0,5 dan telah memenuhi syarat valid sehingga penelitian ini dapat dilanjutkan.

Analisis Data Anti-Image Correlation

Di bawah ini adalah hasil measure of sampling adequacy (MSA) memakai teknik antiImage correlation, telah diolah menggunakan SPSS 16 sebagai berikut :

Tabel 8. Nilai Dari Measures Of Sampling Adequacy (MSA)

\begin{tabular}{|c|c|c|}
\hline No & Indikator & Nilai MSA \\
\hline 1 & Performance (Kinerja) & 0,871 \\
\hline 2 & Features (fitur) & 0,901 \\
\hline 3 & $\begin{array}{l}\text { Conformance to specification (Kesesuaian } \\
\text { dengan spesifikasi) }\end{array}$ & 0,938 \\
\hline 4 & Aesthetics (Estika) & 0,897 \\
\hline 5 & Keterjangkauan Harga & 0,866 \\
\hline 6 & Kewajaran Harga & 0,865 \\
\hline 7 & Kesesuaiian harga dengan kualitas Product. & 0,883 \\
\hline 8 & $\begin{array}{l}\text { Kesesuian harga dengan kegunaan yang } \\
\text { dihasilkan }\end{array}$ & 0,864 \\
\hline 9 & Akses & 0,868 \\
\hline 10 & Visibilitas & 0,893 \\
\hline 11 & Lalu lintas (traffic) & 0,898 \\
\hline 12 & Tempat parkir yang luas dan aman & 0,870 \\
\hline 13 & Lingkungan & 0,920 \\
\hline 14 & Advertising (Iklan) & 0,896 \\
\hline 15 & Personal Selling (Penjualan pribadi) & 0,857 \\
\hline 16 & Promosi penjualan & 0,847 \\
\hline 17 & Publisitas dan hubungan Masyarakat & 0,860 \\
\hline 18 & $\begin{array}{l}\text { Word of mounth (Informasi dari mulut ke } \\
\text { mulut) }\end{array}$ & 0,906 \\
\hline 19 & Pemasaran langsung & 0,816 \\
\hline
\end{tabular}

Tabel 8 menjelaskan dari 19 indikator mempunyai nilai MSA 0,5 dengan demikian 19 indikator tersebut dapat dinyatakan valid. Item-item pernyataan yang telah valid dapat mempresentasikan dengan baik dan dapat dilakukan untuk proses analisis faktor selanjutnya. 
Ekstraksi Faktor ( Penentuan Jumlah Faktor )

Penetapan jumlah faktor bisa dilihat dari angka eigen value yang melebihi dari satu. Total yang dihasilkan dari kualifikasi ini ada empat faktor yang bisa diamati pada Tabel total variance explained dibawah ini:

Tabel 9. Hasil Nilai Total variance explained

\begin{tabular}{|c|c|c|c|c|c|c|c|c|c|}
\hline \multirow[b]{2}{*}{ Comp } & \multicolumn{3}{|c|}{ Initial Eigenvalues } & \multicolumn{3}{|c|}{ Extraction Sums of Squared Loadings } & \multicolumn{3}{|c|}{ Rotation Sums of Squared Loadings } \\
\hline & Total & $\begin{array}{c}\% \text { of } \\
\text { Variance }\end{array}$ & $\begin{array}{c}\text { Cumulative } \\
\%\end{array}$ & Total & $\begin{array}{c}\% \text { of } \\
\text { Variance }\end{array}$ & $\begin{array}{c}\text { Cumulative } \\
\%\end{array}$ & Total & $\begin{array}{c}\% \text { of } \\
\text { Variance }\end{array}$ & $\begin{array}{c}\text { Cumulative } \\
\%\end{array}$ \\
\hline 1 & 8.761 & 46.111 & 46.111 & 8.761 & 46.111 & 46.111 & 4.257 & 22.405 & 22.405 \\
\hline 2 & 1.575 & 8.291 & 54.402 & 1.575 & 8.291 & 54.402 & 3.507 & 18.460 & 40.865 \\
\hline 3 & 1.159 & 6.101 & 60.504 & 1.159 & 6.101 & 60.504 & 2.467 & 12.986 & 53.851 \\
\hline 4 & 1.067 & 5.615 & 66.118 & 1.067 & 5.615 & 66.118 & 2.331 & 12.267 & 66.118 \\
\hline 5 & .830 & 4.367 & 70.485 & & & & & & \\
\hline 6 & .778 & 4.093 & 74.578 & & & & & & \\
\hline 7 & .695 & 3.656 & 78.235 & & & & & & \\
\hline 8 & 608 & 3.200 & 81.434 & & & & & & \\
\hline 9 & .555 & 2.923 & 84.357 & & & & & & \\
\hline 10 & .523 & 2.752 & 87.109 & & & & & & \\
\hline 11 & .422 & 2.219 & 89.329 & & & & & & \\
\hline 12 & .407 & 2.141 & 91.469 & & & & & & \\
\hline 13 & .350 & 1.843 & 93.312 & & & & & & \\
\hline 14 & .312 & 1.644 & 94.956 & & & & & & \\
\hline 15 & .286 & 1.507 & 96.462 & & & & & & \\
\hline 16 & .202 & 1.062 & 97.525 & & & & & & \\
\hline 17 & .169 & .888 & 98.413 & & & & & & \\
\hline 18 & .166 & .871 & 99.285 & & & & & & \\
\hline 19 & .136 & .715 & 100.000 & & & & & & \\
\hline
\end{tabular}

Sumber : Hasil Pengolahan Data SPSS16, Peneliti 2020

Setelah mengetahui faktor yang terbentuk pada tabel 9 selanjutnya menganalisis indikator mana saja yang bisa terbentuk dan di bagi menjadi beberapa faktor dengan melihat nilai faktor loading yang tertinggi disetiap faktornya dengan menghasilkan Roated Componeent Matriix minimum 0.5. Untuk lebih jelasnya dapat dilihat pada tabel Roated Componeent Matriix berikut ini: 


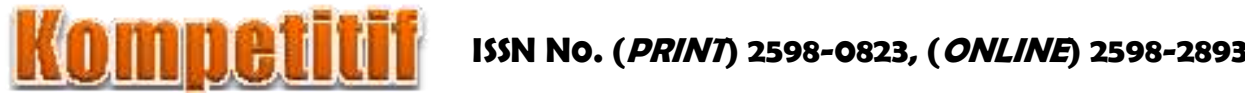

Tabel 10. Rotated Component Matrixa

\begin{tabular}{|c|c|c|c|c|}
\hline & \multicolumn{4}{|c|}{ Component } \\
\hline & 1 & 2 & 3 & 4 \\
\hline Ferformanoe (Kinerja) & .712 & .245 & .376 & .056 \\
\hline Features (fitur) & $143^{-1}$ & .151 & .619 & $16 \overline{1}$ \\
\hline $\begin{array}{l}\text { Conformance to specification (Kesesuaian } \\
\text { denganspesifk asi) }\end{array}$ & .624 & .278 & .313 & 260 \\
\hline Aesthetios (Estra) & .708 & .404 & .059 & 205 \\
\hline Keterjangkauan Harga & .417 & .154 & 697 & .085 \\
\hline Kemajaran Harga & .349 & .234 & .649 & 200 \\
\hline Kesesuaian harga dengankualitas produdt & .655 & .351 & .321 & -.012 \\
\hline $\begin{array}{l}\text { Kesesuaian harga dengan manfaat yang } \\
\text { dihasikan }\end{array}$ & .392 & .601 & 309 & .047 \\
\hline Akses & $18 \overline{0}$ & .792 & .133 & .030 \\
\hline Msibilas & 209 & .740 & .120 & 202 \\
\hline Lalu lintas (trams) & 544 & 245 & $255^{-}$ & $170^{-}$ \\
\hline Tempat park ir yangluas dan aman & .651 & $.38 \mathbf{B}^{-1}$ & $.070^{-}$ & $.149^{-}$ \\
\hline Lingkungan & Est & .029 & 345 & 241 \\
\hline Adverting (lklany & 255 & .692 & .152 & 261 \\
\hline Fersonal Selling (Penjualan pribado & .150 & $\mathrm{Eg} 9$ & .119 & 471 \\
\hline F'romosi penjualan & -.014 & $.460^{-}$ & 367 & 628 \\
\hline Fubititas dan hubungan hasyarakat & .268 & .191 & .213 & 80 \\
\hline $\begin{array}{l}\text { lorod of mounth (riformasi dari mulut ke } \\
\text { mulut) }\end{array}$ & .623 & -.020 & .085 & .389 \\
\hline Pemasaran langsung & 426 & 215 & .039 & .710 \\
\hline
\end{tabular}

Sumber : Hasil Pengolahan Data SPSS16, Peneliti 2020

Pada tabel 10 menjelaskan telah ditemukan empat faktor yang terbentuk, kemudian ditabel componen Matriks menjelaskan terdapat 19 indikator. Faktor yang terbentuk menujukan tingginya nilai dari setiap faktor dan ditentukan sebagai penentu disetiap faktornya. Kemudian nilai faktor yang sangat besar terdapat pada indikator Features (fitur) sebesar 0,819 dan ada pada kolom dua sehingga masuk kedalam faktor tiga dikarenakan angka tersebut ada pada faktor tiga dan yang menjadi faktor satu yaitu ferformance dengan nilai 0,712 sebab ada pada kolom satu dan mempunya nilai tertinggi di faktonya. Nilai faktor ditentukan cara melihat nilai faktor yang terbesar disetiap faktornya yang sudah ditandai dengan ditebalkan. Agar makin ringkas lagi bisa diperhatikan pada tabel distribusii indikator sebagai berikut : 
ISSN NO. (PRINT) 2598-0823, (ONLINE) 2598-2893

Tabel 11. Hasil Analisis Faktor Berdasarkan Rotasi Varimax

\begin{tabular}{|c|c|c|c|c|c|c|}
\hline Faktor & $\begin{array}{l}\text { Nama } \\
\text { Faktor }\end{array}$ & Dimensi & $\begin{array}{l}\text { Loading } \\
\text { Factor }\end{array}$ & $\begin{array}{l}\text { Eigen } \\
\text { Value }\end{array}$ & $\begin{array}{l}\% \text { of } \\
\text { Variance }\end{array}$ & Cumulative \\
\hline \multirow{10}{*}{$\begin{array}{c}\text { Faktor } \\
1\end{array}$} & \multirow{10}{*}{$\begin{array}{c}\text { Performance } \\
\text { (Kinerja) }\end{array}$} & $\begin{array}{l}\text { - Performance } \\
\text { (Kineria) }\end{array}$ & 0,712 & \multirow[t]{10}{*}{8,761} & \multirow[t]{10}{*}{46,111} & \multirow[t]{10}{*}{46,111} \\
\hline & & $\begin{array}{l}\text { - Aesthetics } \\
\text { (Estika) }\end{array}$ & 0,708 & & & \\
\hline & & - Lingkungan & 0,657 & & & \\
\hline & & $\begin{array}{l}\text { - Kesesuaian } \\
\text { Harga dengan } \\
\text { Kualitas }\end{array}$ & 0,655 & & & \\
\hline & & $\begin{array}{l}\text { Produk } \\
\text { - Tempat } \\
\text { parkir yang }\end{array}$ & 0,651 & & & \\
\hline & & luas dan aman & 0,624 & & & \\
\hline & & $\begin{array}{l}\text { - Conformance } \\
\text { to specification } \\
\text { (Kesesuaian } \\
\text { dengan } \\
\text { spesifikasi) }\end{array}$ & & & & \\
\hline & & $\begin{array}{l}\text { - Word of } \\
\text { mount ( } \\
\text { informasi dari } \\
\text { mulut ke } \\
\text { mulut) }\end{array}$ & 0,623 & & & \\
\hline & & $\begin{array}{l}\text { - Lalu lintas } \\
\text { (traffic) }\end{array}$ & 0,544 & & & \\
\hline & & $\begin{array}{l}\text { - Pemasaran } \\
\text { langsung }\end{array}$ & 0,426 & & & \\
\hline \multirow[b]{5}{*}{$\begin{array}{l}\text { Faktor } \\
2\end{array}$} & \multirow[b]{5}{*}{ Akses } & - Akses & 0,792 & \multirow[t]{5}{*}{1,575} & \multirow[t]{5}{*}{8,291} & \multirow[t]{5}{*}{54,402} \\
\hline & & - Visibilitas & 0,740 & & & \\
\hline & & $\begin{array}{l}\text { - Personal } \\
\text { selling }\end{array}$ & 0,689 & & & \\
\hline & & (Penjualan & 0,682 & & & \\
\hline & & $\begin{array}{l}\text { pribadi) } \\
\text { - Advertising } \\
\text { (Iklan) } \\
\text { - Kesesuian } \\
\text { Harga dengan } \\
\text { manfaat yang } \\
\text { dihasilkan }\end{array}$ & 0,601 & & & \\
\hline \multirow{3}{*}{$\begin{array}{l}\text { Faktor } \\
3\end{array}$} & \multirow{3}{*}{$\begin{array}{l}\text { Features } \\
\text { (fitur) }\end{array}$} & $\begin{array}{l}\text { - Features } \\
\text { (fitur) }\end{array}$ & $\begin{array}{l}0,819 \\
0,697\end{array}$ & \multirow[t]{3}{*}{1,159} & \multirow[t]{3}{*}{6,101} & \multirow[t]{3}{*}{60,504} \\
\hline & & - & 0,649 & & & \\
\hline & & $\begin{array}{l}\text { Keterjangkaua } \\
\text { n Harga } \\
\text { - Kewajaran } \\
\text { Harga }\end{array}$ & & & & \\
\hline Faktor & Publisitas & - Publisitas & 0,806 & 1,067 & 5,615 & 66,118 \\
\hline
\end{tabular}


ISSN NO. (PRINT) 2598-0823, (ONLINE) 2598-2893

4

$\begin{array}{cll}\text { dan } & \text { dan hubungan } & \\ \text { hubungan } & \text { Masyarakat } & 0,628 \\ \text { Masyarakat } & \text { - Promosi } & \\ & \text { Penjualan } & \end{array}$

Sumber: Hasil Pengolahan Data SPSS16, Peneliti 2020

\section{E. KESIMPULAN}

\section{Kesimpulan}

Dengan hasil penelitian dan pembahasan yang di dapatkan yaitu faktor-faktor penentu keputusan pembelian pada Kedai Kopi Nol Derajat Cikampek Karawang. maka dari hal yang bisa penulis jadikan kesimpulan adalah : (a) Perfomance (kinerja), akses, features (fitur) dan publisitas dan hubungan masyarakat merupakan faktor-faktor penentu keputusan pembelian pada kedai kopi nol derajat Cikampek Karawang. faktor- faktor yang didapatkan dalam penelitian ini dapat sebagai penentu konsumen dalam keputusan pembelian pada Kedai Kopi Nol derajat Cikampek Karawang sebesar 66,118\%, yang diartikan bahwa terbentuknya faktor-faktor tersebut dianggap sebagai penentu keputusan pembelian pada kedai Kopi Nol derajat Cikampek Karawang. (b) Faktor yang dominan sebagai penentu keputusan pembelian pada kedai Kopi Nol derajat Cikampek Karawang yaitu faktor Perfomance (kinerja) yang memiliki eigen value terbanyak atau tertinggi yang mampu untuk menjelaskan proses keputusan pembelian pada kedai Kopi Nol derajat Cikampek Kawarang sebesar $46,111 \%$ atau lebih banyak dari pada ketiga faktor yang terbentuk lainya.

\section{Saran}

Saran-saran yang bisa ditemukan bagi peneliti kaitannya dengan peneliti perihal kajian faktor-faktor penentu Keputusan Pembelian pada Kedai Kopi Nol derajat Cikampek Karawang Saran bagi pihak Kedai Kopi Nol derajat

Diharapkan untuk mempertahankan penyajian produk dalam hal rasa atau lainya yang sesuai bagi pengunjung agar semakin menarik pengunjung ke Kedai Kopi Nol Derajat. Hal ini di karenakan factor Performance (kinerja) sebagai factor yang utama terhadap penentu keputusan pembelian pada Kedai Kopi Nol Derajat. Untuk faktor lain seperti publisitas dan hubungan masyarakat agar lebih ditingkatkan kembali. Agar pelanggan tidak bosanbosanya dalam melakukan pembeliannya. Berdasarkan dalam penelitian ini publisitas dan hubungan masyarakat merupakan faktor terendah yang dihasilkan dalam penentu keputusan pembelian pada kedai kopi Nol derajat Cikampek Karawang. 


\section{DAFTAR PUSTAKA}

Adhi, a. i., NP Endang, W. M., \& Shanti , P. (2016). pengaruh factor psikologis terhadap keputusan berkunjung. jurnal Admiinistrasi Bisnis (JAB), Vol 30 NO 1.

Alma, P. B. (2018). Manajemen Pemasaran dan Pemasaran Jasa. Bandung: Alfabeta.

Badri, E. N. (2018). Pengaruh Promosi dan Lokasi terhadap Proses keputusan pembelian pada konsumen Cafe Add Coffe Bandung, Univeristas Pasundan .

Balawera, A. (2013, Desember). Green Marketing Dan Corporate Social Responsibility Pengaruhnya Terhadap Keputusan Pembelian Konsumen Melalui Minat Membeli Produk Organik Di Freshmart Kota Manado. Jurnal Emba, 1(vol 1 no. 4), 21172129.

Goenadhi, L. (2011, Oktober). Faktor-faktor yang mempengaruhi perilaku konsumen dalam keputusan pembelian mobil toyota avanza di Kota Banjarmasin. jurnal Manajemen dan Akuntansi, Vol 12, 155-158.

Gunawan, I. (2017). Metode Penelitian Kuantitatif : Teori dan Praktik (Vol. Ed.1 Cet.5). (Suryani, Ed.) Jakarta: PT. Bumi Aksara.

Harahap, D. A. (2015). analisis faktor-faktor yang mempengaruhi keputusan pembelian konsumen dipajak usu (pajus) Medan. Jurnal Keungan dan bisnis, 227-242.

Lesmana, R. (2017). Pengaruh Citra Perusahaan Terhadap Keputusan Pembelian Konsumen PT. Garuda Indonesia Tbk.(Persero). JIMF (Jurnal IImiah Manajemen Forkamma), 1(1).

Lesmana, R., \& Ayu, S. D. (2019). Pengaruh Kualitas Produk Dan Citra Merek Terhadap Keputusan Pembelian Kosmetik Wardah PT Paragon Tehnology And Innovation. Jurnal Pemasaran Kompetitif, 2(3), 59-72.

Lesmana, R., Widodo, A. S., \& Sunardi, N. (2020). The Formation of Customer Loyalty From Brand Awareness and Perceived Quality through Brand Equity of Xiaomi Smartphone Users in South Tangerang. Jurnal Pemasaran Kompetitif, 4(1), 1-12.

Luhmey, H. R. (2018). Kajian kualitas produk Desain Produk dan Citra merek terhadap keputusan pembelian di hook outlet Kediri. kediri: Universitas Nusantara Persatuan Guru Republik Indonesia.

NST, M. R., \& Yasin, H. (2014). Pengaruh Promosi dan Harga terhadap minat beli perumahan obama PT. Nailah Adi Kurnia Sei Mencirim Medan. Manajemen dan bisnis, 135-143.

Nuryati, (2015). pengaruh kominukasi sekolah dengan orang tuaa dan peran orang tua siswa terhadap hasil belajar muatan matematika semester gasal pada kelas rendah di Sekolah Dasar negeri 1 jagoan tahun pelajaran 2014-2015.

Putri, E. R. (2018). pengaruh kualitas produk dan harga terhadap keputusan pembelian Melalui minat beli (studi pada Konsumen Wardah Cosmetics Indonesia). Yogyakarta, Universitas Sanata Dharma.

Saidani, B \& Arifin, S. (2012). Pengaruh Kualitas Produk Dan Kualitas Layanan Terhadap Kepuasan Konsumen Dan Minat Beli Pada Ranch Market. Jurnal Riset Manajemen Sains Indonesia (JRMSI), 3 (No 1), 5 
Sibarani, C. G., Armayanti, N., Irwansyah, \& Suharianto, J. (2019). DASAR-DASAR KEWIRAUSAHAAN. Yayasan KIta Menulis.

Sunardi, N., \& Lesmana, R. (2020). Konsep Icepower (Wiramadu) sebagai Solusi Wirausaha menuju Desa Sejahtra Mandiri (DMS) pada Masa Pandemi Covid19. JIMF (Jurnal IImiah Manajemen Forkamma), 4(1).

Sunardi, N., Lesmana, R., Kartono, K., \& Rudy, R. (2020). Peran Manajemen Keuangan dan Digital Marketing dalam Upaya Peningkatan Omset Penjualan bagi Umkm Pasar Modern Intermoda Bsd City Kota Tangerang Selatan di Tengah Pandemi Covid-19. Jurnal Abdi Masyarakat Humanis, 2(1).

Susanto, A. (2013). pengaruh promosi harga dan Inovasi produk terhadap keputusan pembelian pada Batik Tulis Karangmlati Demak, Semarang. Universitas Negeri Semarang.

Sutarman, A., \& Lesmana, R. (2019). Analisis Keputusan Pembelian Konsumen dari Sisi Normtif dan Informatif Pada Supermarket Giant Pamulang, Tangerang Selatan. PROCEEDINGS UNIVERSITAS PAMULANG, 1(1).

Suwandana, I. A. (2017). Pengaruh Faktor-faktor kualitas pelayanan terhadap kepuasan nasabah pada koperasi serba usaha dalem kahyangan dukuh desa adat kerobokan di kuta utara, badung. Semnas IIB Darmajaya.

Totok Murdoyo (2014). analisis faktor-faktor yang mempengaruhi konsumen dalam pengambilan keputusan produk sepatu merk Adidas pada pelanggan lapangan Futsal Gor surya di Boyolali. Boyolali: Fakultas ilmu keolahragaan Universitas Negeri Yogyakarta. 